\title{
Dealing with Administrative Discretions in E-Government: A Citizen Consultation Model
}

\author{
Wanchai Varavithya and Vatcharaporn Esichaikul \\ School of Engineering and Technology \\ Asian Institute of Technology, Thailand \\ \{wanchai.varavithya, vatchara\} dait.ac.th
}

\begin{abstract}
This paper presents a citizen consultation model (CICO) to support the citizen participation in the government discretionary decisionmaking process. The aim is not to hollow out discretionary power from officials, but to encourage citizens in putting forward discussions and argumentations to the government in order to lessen arbitrariness and promote the principle of openness and transparency. A participation platform of the CICO is presented and related works are discussed.
\end{abstract}

\section{Administrative discretions}

Public administrative discretion refers to the degree of latitude or flexibility exercised by public administrators when making decisions or conducting any agency business [1]. As such, discretions can be viewed as a source for arbitrariness, unfairness, corruption or irrational outcomes and need to be eradicated. However, this paper argues that taking away discretions from the government might cause an official to ignore citizen-individualized circumstances and thereby overlook special needs of citizens. This paper suggests the open government concept coined by Nelson [2] to bring about transparency and openness in discretionary decision-making. Nelson defines the concept of "open government as "Participation contributes to open government, open government contributes to the need to justify official actions in terms of morally acceptable principles, and the need to justify contributes to better decisions."

With the goal of eliminating the discretionary decision-making by whim, caprice, chance, or ritual, Galligan [3] introduces the concept of consultation as a mode of participation that connotes the presentation of arguments and proof in order to influence the way issues are to be settled. The decision-maker has a duty to hear and consider, but may decide for reasons which go beyond the submissions of the parties, and may act according to standards which are defined only broadly or settled only in the course of the decision.

With the aim of promoting the concept of open government, this paper proposes an e-government discretionary framework in Table 1. The framework 
describes collaboration activities based on two dimensions: the citizen consultation process and the administrative decisions as classified by Galligan [3]. The level of discretions emphasizes that the use of discretions is low in the adjudication decisions where the rules are clear and explicit. However, discretions play a partial role in the modified adjudication, as it has to deal with how person or situations are to be treated. In the policy issue decisions, discretion is vital in the decision-making processes, not only to an official but also to citizens who must exercise discretions through voting, public hearing, etc. The e-government discretionary framework can be used as a lens to analyze and design coordination and collaborative activities in the discretionary egovernment problem domains.

Table 1. The e-government discretionary framework.

\begin{tabular}{|c|c|c|c|c|c|}
\hline & \multirow[b]{2}{*}{$\begin{array}{l}\text { Classification } \\
\text { of discretionary } \\
\text { decisions* }\end{array}$} & \multicolumn{3}{|c|}{ Citizen Consultation Process } \\
\hline & & & $\begin{array}{l}\text { Phase 1) } \\
\text { Disclosure of } \\
\text { facts and } \\
\text { evidence } \\
\text { before } \\
\text { decision }\end{array}$ & $\begin{array}{l}\text { Phase 2) } \\
\text { Formulate or } \\
\text { apply existing } \\
\text { standards, and } \\
\text { make } \\
\text { decisions }\end{array}$ & $\begin{array}{l}\text { Phase 3) Issue } \\
\text { legal decision } \\
\text { and appealing } \\
\text { procedures }\end{array}$ \\
\hline \multirow{3}{*}{$\begin{array}{l}0 \\
.00 \\
0 \\
0 \\
0 \\
0 \\
0 \\
0 \\
0\end{array}$} & $\begin{array}{l}3 \\
0 \\
3 \\
3\end{array}$ & Adjudication & $\begin{array}{l}\text { Inform of } \\
\text { applicable } \\
\text { rules, } \\
\text { evidences, fact } \\
\text { of the case. }\end{array}$ & $\begin{array}{l}\text { Apply existing } \\
\text { standards to } \\
\text { the fact of the } \\
\text { case. }\end{array}$ & $\begin{array}{l}\text { Issue a } \\
\text { statement of } \\
\text { reasons }\end{array}$ \\
\hline & 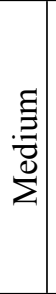 & $\begin{array}{l}\text { Modified } \\
\text { Adjudication }\end{array}$ & $\begin{array}{l}\text { Propose, } \\
\text { argue, debate } \\
\text { on reasons, } \\
\text { facts, evidence } \\
\text { and 'open- } \\
\text { texture' } \\
\text { language. }\end{array}$ & $\begin{array}{l}\text { Formulate a } \\
\text { new set of } \\
\text { standards or } \\
\text { apply existing } \\
\text { standards } \\
\text { based on merit } \\
\text { of the case. }\end{array}$ & $\begin{array}{l}\text { Collaborative } \\
\text { writing and } \\
\text { issuing a } \\
\text { statement of } \\
\text { reasons }\end{array}$ \\
\hline & . & Policy Issue & $\begin{array}{l}\text { Notify or } \\
\text { educate public } \\
\text { of rights and } \\
\text { obligations } \\
\text { under the laws. }\end{array}$ & $\begin{array}{l}\text { Make decision } \\
\text { through voting } \\
\text { or signing } \\
\text { petition. }\end{array}$ & $\begin{array}{l}\text { View, verify, } \\
\text { or track results } \\
\text { of a decision- } \\
\text { making }\end{array}$ \\
\hline
\end{tabular}

* Adapted from Galligan [3]

\section{Citizen Consultation Model}

As modified adjudication decisions represent a large portion of decisions entrusted to an official [3], this paper intends to design a citizen consultation 
model (CICO) to support every step of the citizen consultation process under the modified adjudication decision shown in Table 1. Samples in this type of decisions can be found in business registration services, social welfare, immigration, police, deportation, etc. The special requirements are:

- An official is a person who is held accountable for decision outcomes.

- Decision-making is aimed at a citizen-individualized problem in relation to his or her situation, not at a general public issue.

- In certain cases, a decision-maker is required to formulate a new set of standards, which could be flexible, unpredictable, and difficult to model.

- The combination of adjudicative (i.e. rules of law) and discretionary element is necessary

Based on the above requirements, $\mathrm{CICO}$ has three prime objectives: first, to provide a platform in order to facilitate discussions and argumentations amongst participants; second, to assist a discretionary decision-maker in formulating a new set of standard; and third, to advise the best alternative to a decision-maker. The CICO conceptual model is depicted in figure 1.

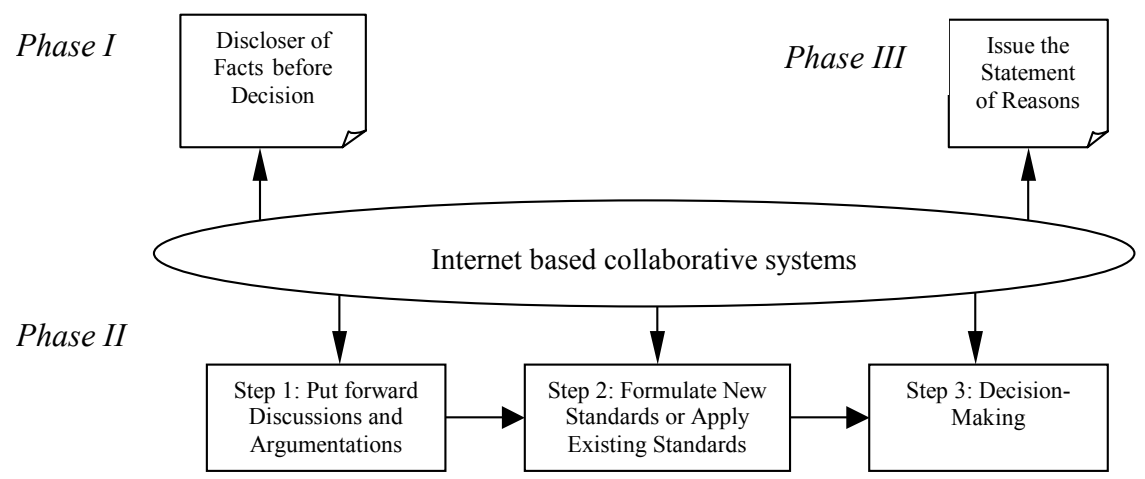

Figure 1. CICO conceptual model.

This paper presents only Step 1 of Phase II or the participation platform to facilitate participants who take part in the consultation processes and leave Step 2 and Step 3 for future works. In Step 1, instead of using a normal web forum, i.e. chat-room, web board that are simple but often lead to chaos, the semi-formal approach is applied with an intend to let participants thinks and discuss the issue within a certain knowledge representation framework. A semi-formal vocabulary of Decision Representation Language (DRL) developed by Lee and Lai [4] is selected as a language for representing discussions and argumentations. DRL was implemented in SIBYL, a tool for managing group decision rationale similar to a knowledge-based system which provides services for the management of dependency, uncertainty, view points, and precedents [5]. The strength of DRL is the tendency to instigate people to be aware of the decision objectives against 
which alternatives in relation to explicit goals and be able to evaluate each alternative in order to make decisions. It also allows the user to formulate arguments to support or deny claims. The basic elements of decision-making in DRL are:

- A decision problem represents a decision issue or a problem of choosing the alternative that best satisfies the goals.

- Alternatives represent options from which to choose or a possible solution to a decision problem.

- Goals represent properties that an ideal option should have.

- Claims represent the means of argumentation, which puts forward in the relation to alternatives and goals (i.e. supports or denies).

- Questions/Answers present interest or a means for carrying out discussions.

In order to keep the whole discussions and arguments in a knowledge base, argumentations in DRL knowledge representation will be transformed into the first-order predicate calculus as shown in Figure 2.

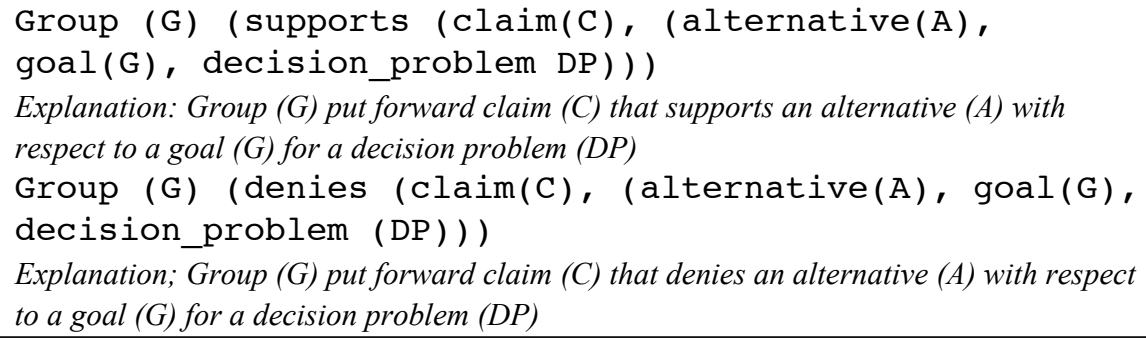

Figure 2. DRL knowledge representation in first-order predicate calculus.

The citizen consultation room screen capture is illustrated in figure 3 . This room is intended to provide an easy to use interface similar to public discussions via chat rooms. Before the starting of phase II of the citizen consultation process, an official who acts as a moderator must designate an instance of promulgation, case identification, groups and names of participants, and start date and due date, an instance for a decision problem, alternatives, and goals. Participants can always use a mouse to point at a DRL argumentation element and use the rightmouse button to initiate the corresponded elements, i.e. a new decision problem, sub-alternatives, sub-goals, questions \& answers and can enter text statement or upload file down the root node of the hierarchical structure graph. This way, participants can influence the nature of decision problem, alternatives, and goals, and decide whether it should include more or cross out any unnecessary alternatives or goals

The next step is shown in figure 4 or the decision matrix room screen capture, where participants can solicit their opinions or put forward discussions and argumentations by appraising an alternative with respect to a goal. Participants 
express their claim arguments as 'supports' or 'denies' and can initiate a discussion by posting questions or answers instance. The citizen consultation system facilitates the argument polarize feature for participants by clicking a tap control and viewing the whole set of arguments in three different views: alternatives, goals, and participant point of views. This feature helps participants gain a full understanding of the case and thereby enhances the openness principal. Participants may put before the decision-maker an argument that may compete or rebut each other in an equal of opportunity mode of participation.

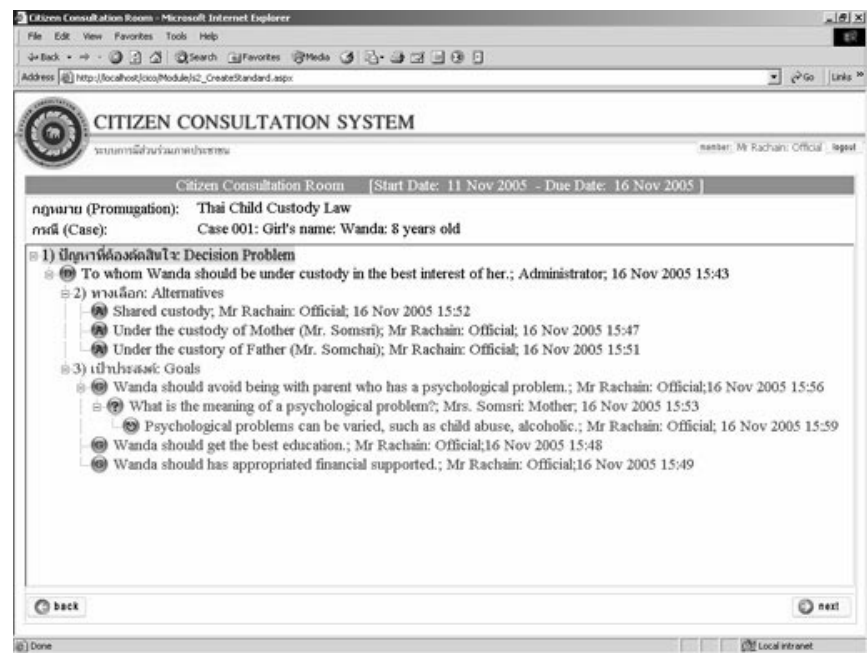

Figure 3. Sample screen of the citizen consultation room.

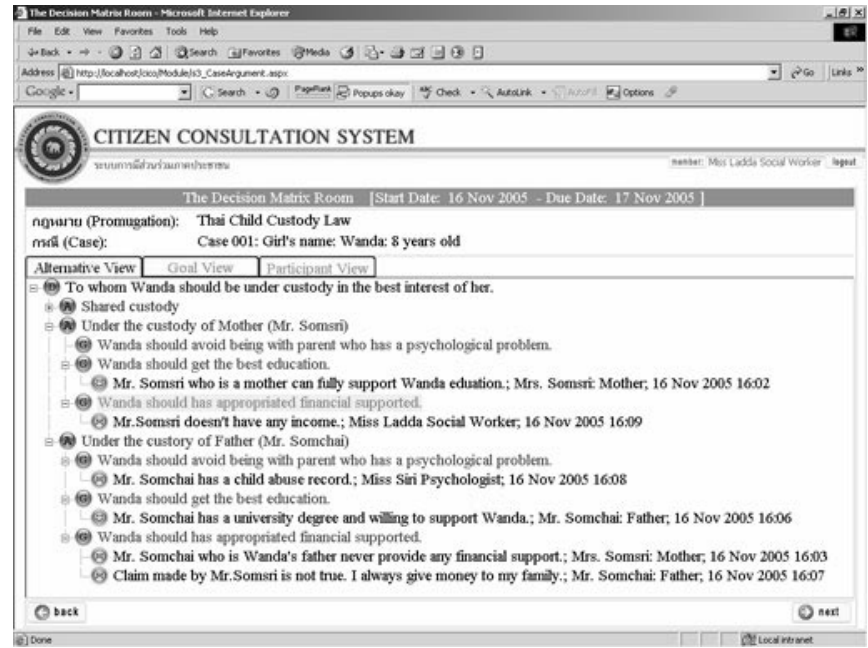

Figure 4. Sample screen of the decision matrix room. 
In order to facilitate not only a communication channel as presented in Step 1, but also a decision advisory in Step 2 and Step 3 of figure 1, the following assumptions must be taken into account:

- Some officials may prefer to make decisions not by logical conclusions but by combining factors in their own ways that present or represent features in favour of the conclusion of the case [6], [7].

- The formulation of new standards must consider the merit of the cases.

- The probabilistic reasoning or fuzzy sets must be applied with caution, as it may not be suitable to the nature of legal decision-making [7].

- Previous decision-making experiences, such as success or failure, can contribute to the transparency and fairness principle [3].

- Irrelevant, unreasonable, or even untrustworthy arguments proposed by participants are possible.

\section{Related works}

Based on the implementation of DRL in CICO, an argumentation-based reasoning seems to be a prime candidate technique for our future works. The basic question is to determine how far the reasoning technique can provide in an attempt to automate the CICO in the discretionary context. An argumentation theory has greatly contributed to the development of artificial intelligence application in law, which aims at structuring knowledge representation and modeling dialectical reasoning. Stranieri et al. [8] used the generic/actual argument model to predict judicial decisions regarding a property split following divorce under Australia law. The argumentation theory of Toulmin [9] was applied in the development of the Split-Up systems [10]. The argumentation based representation is central to the Split-Up system, which is used to structure Australian family law to be generated and enables the task of determining the percentage split of assets to award each party of a failed marriage by integrating rule-based reasoning and neural networks into one seamless system.

EMBRACE is a legal knowledge based systems that deal directly with discretion issues in the Australia Refugee Law [11]. EMBRACE is constructed based on the argument structure of Toulmin as in the Split-Up system. Its framework is intended to capture arguments within the Australia Refugee Law and facilitates the integration of information gathering and retrieval for the purpose of argument construction and drafting. However, the system does not attempt to automatically interpret information retrieved related to any specific argument, but facilitates the validation and substantiation of data, claims and their values by users.

Issue-Based Information Systems [12] is a vital argumentation-based model. IBIS elements consist of an issue (decisions to be made or goals to be achieved), positions (data that have been brought up to declare alternative option), and constraints (preference relations between two positions). SIBYL [5], which is an extension of gIBIS, is a tool for managing group decision rationale and 
implements using DRL as a representation language. SIBYL allows users to evaluate alternatives with respect to the goals specified in order to make the final decision.

Zeno argumentation framework invented by Gordon and Karacapilidis [13] focuses on the multiple participants who put forward arguments in order to contest and defeat other arguments. GeoMed is a sample of group decision support system for Geographical Mediation on the World Wide Web using Zeno argumentation framework [14]. It supports the collaborative environment planning which is performed through debates, negotiations and argumentation amongst various agents. Mediation services within GeoMed provide an issue based conferencing and group decision support systems. GeoMed's task is not intended to play the role of a cop or judge but acts as an assistant and advisor and leave the final decisions and actions to users to decide.

HERMES system uses similar argumentation elements as GeoMed [15]. In HERMES, the constraint is a key element which represents preference relations that are critical to the argumentation-based reasoning. The primary task of HERMES system is to provide direct computer support for the argumentation, negotiation and mediation process in a group decision-making. It was implemented in Java (applets) and runs on the Web; therefore, it facilitates distributed collaborative discussions. In HERMES, constraint is an important element that provides a qualitative way to weight reasons, which are more (or less) important than or are equally important. Karacapilidis and Papadias emphasize that the mix of human and computer reasoning is still necessary to assist and advise decision makers in HERMES.

Other argumentation-based approach is demonstrated by Zhang et al. [16] who developed the frame-based argumentation information structure and implement in a group argumentation support system prototype (FBA-GASS). The proposed frame-based information structured is applied in electronic brainstorming and argumentation to support group decision task generation and identification in organization. Decision can be reached via a consensus or voting.

From the reviews of the argumentation-based reasoning systems, the technique is very useful in facilitating and structuring citizen discussions and argumentations. It is also practical in the transformation of arguments into a FOB to be kept in a knowledge-base. Argumentation techniques encourage a decision-maker to think thoroughly and make decisions in a reasonable and intelligent manner. Furthermore, citizen can see through the whole set of arguments for the purpose of scrutiny and supervision, which can efficaciously prevent the elements of arbitrariness and ensure that people interests are taken into account.

However, in the discretionary decision-making context, there are still several problems to be solved. First, despite the fact that the argumentation technique is an effective tool to structure argumentation knowledge, it is still difficult to model a reasoning mechanism for unfettered discretionary domains [17]. Second, discussions and argumentations proposed by citizens may not always be logically valid, and therefore cannot automatically transform premises to reach 
the conclusion using logic calculations. Third, argumentation-based reasoning does not take past experiences into consideration; hence, the principle of transparency and fairness cannot be fully achieved.

To incorporate past experience into $\mathrm{CICO}$, the case based reasoning technique [18] is a logical choice to supplement the argumentation-based reasoning. Karacapilidis et al. [19] have demonstrated the integrated framework of a casebased reasoning and an argumentation-based reasoning technique for group decision processes. The framework addresses the presence of various selection criteria, preferences, goals, etc. as viewpoints that can evolve over time. The integration of CBR techniques aims at supporting agents involved in group decision-making processes to retrieve, adapt, and re-use old cases at a part of a discussion episode. However, the framework is not intended to use CBR to support the decision-making purpose.

\section{Conclusion and Future works}

This paper illustrates rationales and a partial development of CICO that aims to support citizen participations in the administrative discretions in e-government. In Step 1, CICO adopted the DRL [4] as a language for representing discussions and argumentations.

Our future works will focus on the design and development of CICO systems in Step 2 and Step 3 using the argumentation-based technique for knowledge representations and CBR techniques for decision support reasoning. In the future, good governance evaluations (i.e. transparency and openness) in a modified adjudication type of decision-making are necessary. The real government setting in the child adoption services and rule of origin verification services is planned.

\section{References}

1. Warren K.F.: Encyclopaedia of Public Administration and Public Policy, ISBN: 08247-4240-0 (2003), pp. 35-38.

2. Nelson W.N.: Justifying Democracy, Referred to in Galligan D.J. Discretionary Powers A Legal Study of Official Discretion, Clarendon Press, Oxford (1990).

3. Galligan D.J.: Discretionary Powers A Legal Study of Official Discretion, Clarendon Press, Oxford (1990).

4. Lee J. and Lai K.: What's in design rationale, Human-Computer Interaction, Vol. 6, No. 3-4 (1991), pp. 251-280.

5. Lee J., SIBYL: A tool for managing group decision rationale, Artificial Intelligence at MIT: Expanding Frontiers, the MIT press (1990), pp. 104-133.

6. Christie G.C.: An essay on discretion, Duke Law Journal (1986), pp. 747-778.

7. Gardner A.L.: An Artificial Intelligence Approach to Legal Reasoning, MIT Press (1987). 
8. Stranieri A., Zeleznikow J., Gawler M., and Lewis B.: A hybrid rule-neural approach for the automation of legal reasoning in the discretionary domain law in Australia, Artificial Intelligence and Law, Vol.7, No. 2-3 (1999), pp. 153-183.

9. Toulmin S.: The Users of Arguments, Cambridge, University Press (1958).

10. Zeleznikow J. and Stranieri S.: The Split-up Systems: integrating neural networks and rule-based reasoning in the legal domain, In proceedings of the 5th International Conference on Artificial Intelligence and Law (1995), pp. 185-194.

11. Yearwood J.L. and Stranieri A.: The integration of retrieval, reasoning and drafting for refugee law: a third generation legal knowledge based system, In proceeding of ICAIL, Oslo, Norway, ACM (1999).

12. Kunz W. and Rittel H.W.J.: Issues as elements of information systems, Working paper, No. 0131, University Stuttgart (1970).

13. Gordon T. and Karacapilidis N.: The Zeno argumentation framework, In proceedings of the Sixth International Conference on Artificial Intelligence and Law, ACM Press (1997), pp. 10-18.

14. Karacapilidis N., Papadias D., Gordon T., and Voss H.: Collaborative environmental planning with GeoMed, European Journal of Operational Research, Vol. 102, No 2 (1997), pp. 335-346.

15. Karacapilidis N. and Papadias D.: Computer supported argumentation and collaborative decision making: the HERMES system, Information System, Vol. 26 (2001), pp. 259-277.

16. Zhang P., Sun J., and Chen H.: Frame-based argumentation for group decision task generation and identification, Decision Support Systems, Vol. 39 (2005) 643-659

17. Zeleznikow J.: Building Decision Support Systems in Discretionary Legal Domains, International Reviews of Law Computers \& Technology, Vol. 14, No. 3 (2000), pp. 341-356.

18. Kolodner J., Case-Based Reasoning, Morgan Kaufmann Publishers (1993).

19. Karacapilidis N.I., Trousse B., and Papadias D.: Using Case-Based Reasoning for Argumentation with Multiple Viewpoints, In proceedings of the 2nd International Conference on Case-Based Reasoning (ICCBR'97), Providence, Rhode Island, July 25-27, Springer-Verlag, Berlin (1997). 